\title{
A case report of microcephaly and refractory West syndrome associated with WDR62 mutation
}

\author{
Ping Zhou ${ }^{1,2}$, Xin Ding ${ }^{1}$, Qi Zeng ${ }^{1}$, Huafang Zou', Jianxiang Liao ${ }^{1}$ and Dezhi Cao ${ }^{*^{*}}$
}

\begin{abstract}
The autosomal recessive form of primary microcephaly $(\mathrm{MCPH})$ is a rare disorder characterized by microcephaly with variable degree of intellectual disability. WDR62 has been reported as the second causative gene of MCPH2. West syndrome is a severe epilepsy syndrome composed of the triad of spasms, hypsarrhythmia, and mental retardation. There are limited clinical reports regarding WDR62 mutation and West syndrome. Here we report a boy who was identified with WDR62 mutation and was followed up from age 3 months to 5 months and 14 days. He had the first seizure as the classic epileptic spasm at the age of 3 months. Psychomotor retardation was noted before the seizure occurred. The head circumference was $38.5 \mathrm{~cm}$ (SD 2.6) when he was 4 months old, no dysmorphic facial features were observed. He couldn't support his head steadily or turn over. He was able to laugh when tricked by the parents, but couldn't track the sound and light. At the early stage, the electroencephalogram showed multifocal discharges, which evolved into hypsarrhythmia one month later, and brain MRI showed developmental malformation of cerebral gyrus. Two heterozygous mutations were identified in WDR62 by whole exome sequencing c.1535G > A, p.R512Q and c.2618dupT, p.K874Qfs*40. The patient was administrated with oral sodium valproate, nitrazepam, intramuscular adrenocorticotropic hormone for 2 weeks, and followed by prednisone, levetiracetam, topiramate and vigabatrin. However, there was no significant improvement on the seizure control after these treatments. According to the genetic report and clinical manifestation, we speculated that the WDR62 compound heterozygous mutation is responsible for the serious clinical phenotype.
\end{abstract}

Keywords: Autosomal recessive primary microcephaly 2, WDR62, West syndrome, Refractory epilepsy

\section{Background}

WDR62 plays an important role in cerebral cortical development. It is also one of the main pathogenic genes (only after $A S P M$ ) for autosomal recessive primary microcephaly 2 (MCPH2), which is a neurodevelopmental disorder characterized by microcephaly presenting at birth and nonprogressive mental retardation [1-4]. West syndrome is a severe epilepsy syndrome composed of the triad of spasms, interictal hypsarrhythmia shown in electroencephalogram(EEG) and mental retardation. Up

\footnotetext{
*Correspondence: caodezhi888@aliyun.com

'Neurology Department, Shenzhen Children's Hospital, Shenzhen,

Guangdong 518038, China

Full list of author information is available at the end of the article
}

to now, West syndrome has been rarely reported to be related with WDR62 mutation. In this study, we reported a boy with compound heterozygous WDR62 mutations, diagnosed as MCPH2 and West syndrome. The informed consent of the parents and the approval of the ethics committee (SZCH [Article] 2019 /002) were obtained.

\section{Case presentation}

The child patient, male, is the first child of a healthy Chinese genetically unrelated couple. He was born at full term following an uneventful vaginal delivery with length $49 \mathrm{~cm}$ (SD 0.47), weight $3.2 \mathrm{~kg}$ (SD 0.3), and head circumference $32 \mathrm{~cm}$ (SD 2). He reached his normal milestone at

(c) The Author(s). 2020 Open Access This article is licensed under a Creative Commons Attribution 4.0 International License, which permits use, sharing, adaptation, distribution and reproduction in any medium or format, as long as you give appropriate credit to the original author(s) and the source, provide a link to the Creative Commons licence, and indicate if changes were made. The images or other third party material in this article are included in the article's Creative Commons licence, unless indicated otherwise in a credit line to the material. If material is not included in the article's Creative Commons licence and your intended use is not permitted by statutory regulation or exceeds the permitted use, you will need to obtain permission directly from the copyright holder. To view a copy of this licence, visit http://creativecommons.org/licenses/by/4.0/. 
the age of 2 months. He was able to hold head, track light or sound, and laugh initiatively. But the parents noticed that he lost the ability to hold head steadily and couldn't track light or sound by the age of 4 months.

At the age of 4 months, the boy was hospitalized because of recurrent seizures including focal seizure and epileptic spasm. His body weight and head circumference were $6.5 \mathrm{~kg}$ (SD 0.68) and $38.5 \mathrm{~cm}$ (SD 2.6) respectively. On physical examination, one cafe-au-lait macule $\left(8 \times 4 \mathrm{~cm}^{2}\right)$ on the left thigh and one hemangioma (about $2 \times 2 \mathrm{~cm}^{2}$ ) on the neck were noted. Muscle tone was slightly lower than normal in all extremities.

Head magnetic resonance imaging (MRI) at 3 months and 13 days (Fig. 1) showed neuronal migration disorder and multiple gyrus malformations. Shallow sulci, widened gyri and thickened bilateral cerebral cortex were noticed in both cerebral hemispheres, and polymicrogyria in some areas. The first EEG was performed at 3 months and 12 days. It showed many sharp waves during wakefulness and sleep, which were asymmetrical and predominant at the posterior area, sometimes simultaneously appeared in the central and mid-temporal areas. The second EEG was performed at 4 months and 20 days (Fig. 2), which indicated hypsarrhythmia during sleep and wakefulness. Clinical epileptic spasms were identified during this EEG recording.
The trios whole exome sequencing (WES) [5] of the family were performed at 4 months and 18 days (Running Gene Inc). Two heterozygous variants were identified in the WDR62: c.1535G > A, p.R512Q, inherited from the mother; c.2618dupT, p.K874Qfs*40, inherited from the father (Fig. 3). These two variants had not been reported in literatures, and the frequency in the healthy population was very low. The p.K874Qfs*40 is a frameshift mutation that leads to the early termination of protein translation and may have a great effect on protein function. American College of Medical Genetics and Genomics (ACMG) variation rating is likely pathogenic. The p.R512Q is a missense mutation, and the amino acid is well conservative, which may affect the function of protein (Mutation Taster: disease causing, 0.999; PolyPhen-2: probably damaging, 0.998; SIFT: damaging, 0.037). ACMG variation rating is variation uncertain significance (VUS). The phenotype of the child was consistent with the phenotype and genetic pattern of WDR62 mutation that had been reported, so the WDR62 compound heterozygous mutation in our study were considered to be pathogenic.

The patient was administered sodium valproate (18.4 $\mathrm{mg} / \mathrm{kg} / \mathrm{d}$ ) and nitrazepam (from $0.48 \mathrm{mg} / \mathrm{kg} / \mathrm{d}$ to 1.44 $\mathrm{mg} / \mathrm{kg} / \mathrm{d}$ ) at the early stages of the disease, whereas the seizures were poorly controlled. After 2 weeks of
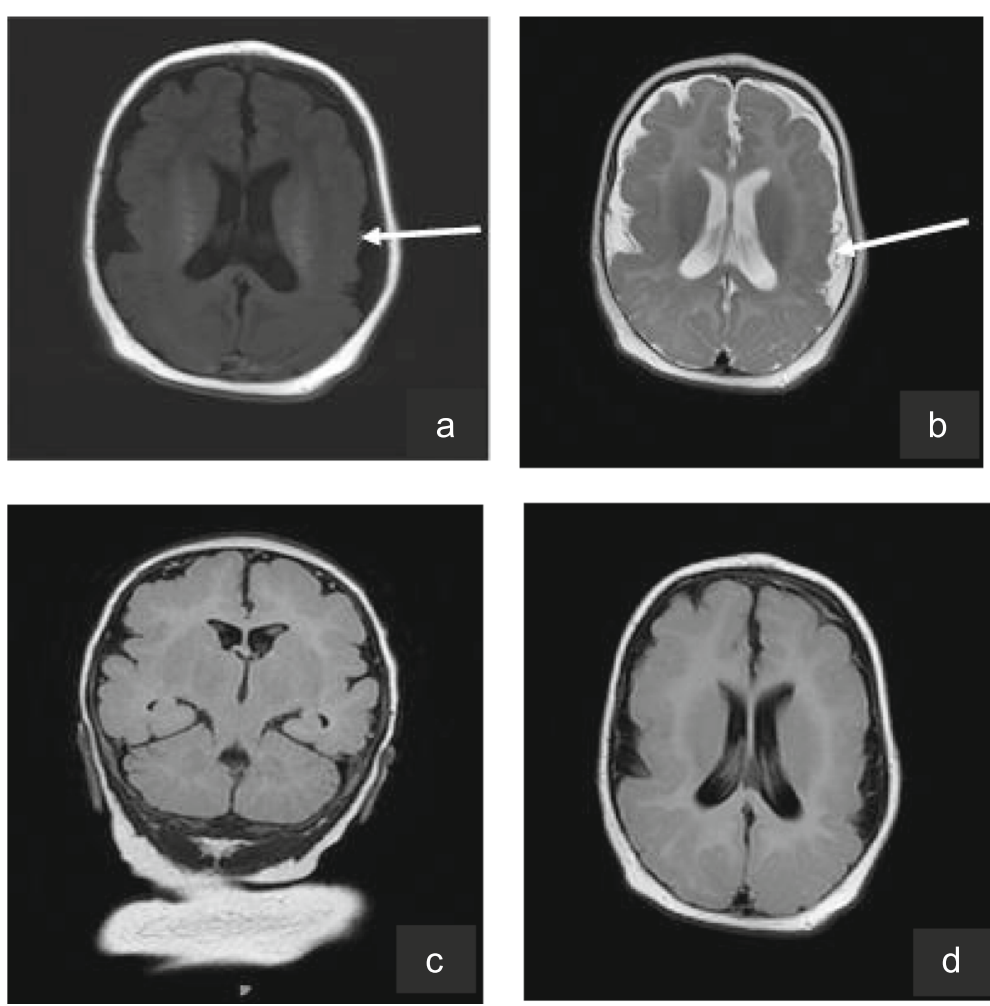

Fig. 1 Brain magnetic resonance imaging (MRI) of the patient. Shallow sulci, widened gyri and thickened bilateral cerebral cortex were noticed in bilateral hemispheres, and polymicrogyria in some areas. (the arrow) a: Axial T1; b: Axial T2; c: Coronal T2 FLAIR; d: Axial T2 FLAIR 


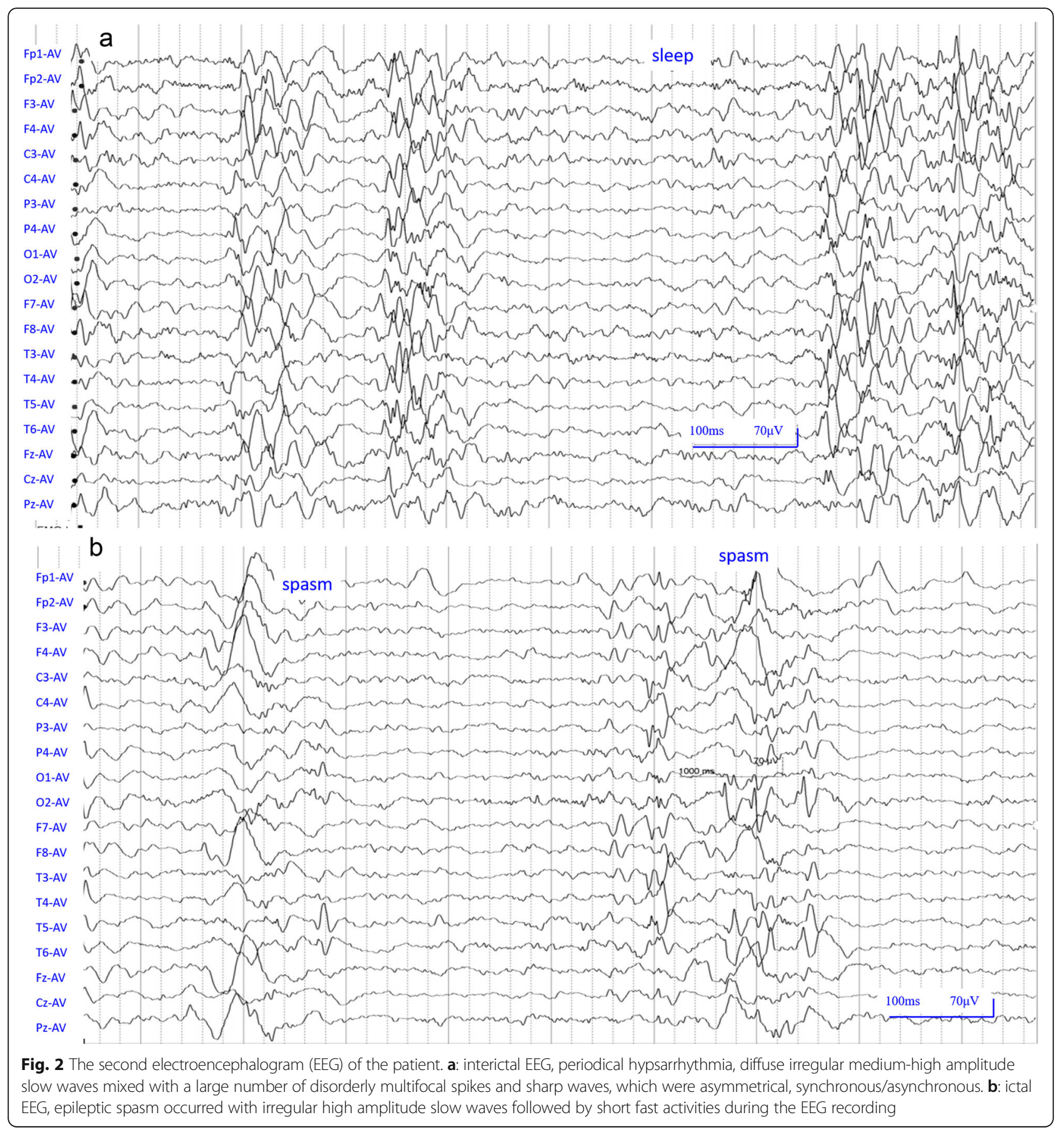

intramuscular adrenocorticotropic hormone (ACTH) therapy $(1 \mathrm{U} / \mathrm{kg}$, twice daily for 1 week then increase to $2 \mathrm{U} / \mathrm{kg}$, twice daily for 1 week), the patient was administered with oral prednisolone $(2 \mathrm{mg} / \mathrm{kg} / \mathrm{d})$, and the seizure frequency was slightly decreased from 3 to 5 series/d to 2-4 series/d. After the administration of levetiracetam $(20 \mathrm{mg} / \mathrm{kg} / \mathrm{d})$, topiramate $(1.92 \mathrm{mg} / \mathrm{kg} / \mathrm{d})$ and vigabatrin $(38.46 \mathrm{mg} / \mathrm{kg} / \mathrm{d})$, the patient still had epileptic spasms, and had a new seizure type manifested as follows: clenched fists with both hands, upper limbs tonic, occurred in series, lasted $2-7 \mathrm{~min}, 6-7$ series/d, which were considered as tonic-spasms. Ketogenic diet was tried and the frequency of seizure was lowered slightly to $4-5$ series/d transiently. Lamotrigine $(0.67 \mathrm{mg} / \mathrm{kg} / \mathrm{d})$ was administered, but withdrawn soon because of transient skin rash and exacerbation of seizure frequency. To relieve the seizure burden, corpus callosotomy was recommended to the parents. However, they refused this operation in consideration of the young age and the possible complications. 
a

c. $1535 \mathrm{G}>\mathrm{A}$

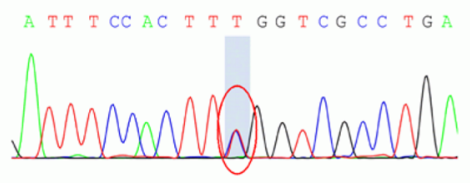

Patient (c.1535G $>A)$

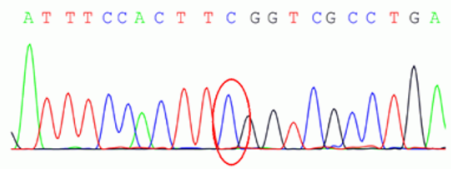

Father (no variant)

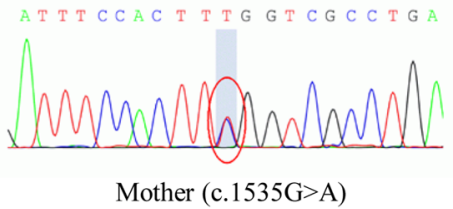

b

c.2618dupT

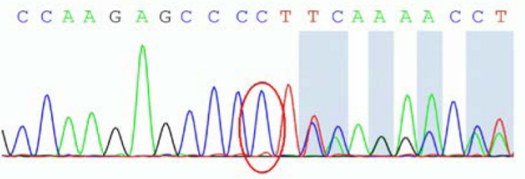

Patient (c.2618dupT)

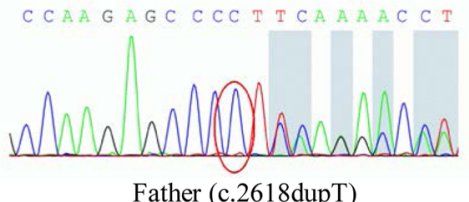

$C C A A G A G C C C C T C A A G A C C A T$

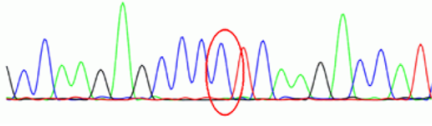

Mother (no variant)

Fig. 3 Sanger sequencing of WDR62 variants of the child patient and his parents. a: The heterozygous mutation c.1535G > A of WDR62 was found in the chr19:36574128 of the child and his mother, but no variant was found at the same locus of his father (circled part); b: The heterozygous mutation c.2618dupT of WDR62 was found in the chr19:36590397 of the child and his father, but no variant was found at the same locus of the mother (circled part)

\section{Discussion}

WDR62 is located in chromosome 19q13.12, composing of 32 exons, encodes 1523 amino acids, and the protein contains multiple WD40 repeats [6, 7]. Mutations in the WDR62 can cause severe cerebral cortical abnormalities, including microcephaly, cerebral gyrus hypertrophy with cortical thickening and dysplasia of corpus callosum $[6,8,9]$, all inherited in an autosomal recessive. A number of neurobehavioral abnormalities have been reported, including psychomotor developmental delay, seizure, aggression and irritability [9-11]. In addition, some case reports claimed that WDR62 mutation can also cause skin changes [12].

Taking "WDR62" and "West syndrome", "WDR62" and "infantile spasms" as the keywords to search on PubMed, we found only one publication by Nardello $\mathrm{R}$ et al. in 2018, which reported WDR62 and GPR56 variants in a patient with $\mathrm{MCPH} 2$. Literatures have reported variable and unstable frequency and severity of seizures in children with WDR62 variant. However, in this case, the severity of seizure and its effect on overall mental function were the major phenotype. This suggested that WDR62 and other mutated genes may work together to regulate the severity of genetic phenotype [13]. Therefore, we cautiously put forward the hypothesis that the combined effect of c.1535G > A and c.2618dupT of WDR62 variants may lead to abnormal change of brain structure in this child, which further lead to refractory epilepsy and psychomotor retardation.
C-terminal of WDR62 has regulatory function, and Nterminal is necessary for spindle microtubule binding. WDR62 could regulate mitotic spindle orientation, centrosome integrity and progression via Aurora kinase and JNK mitogen-activated protein kinase (MAPK) signaling pathway $[7,14]$. In the early stages of the cell cycle, WDR62 is located at the poles of mitotic spindle [12]. Immunocytochemistry studies have shown that WDR62 exhibits cytoplasmic distribution during the intermitotic phase, but accumulates in large quantities at the spindle poles during mitosis. The reduced proteins caused by WDR62 mutation fail to locate at the poles of the mitotic spindle, resulting in the destruction of the asymmetric inheritance of the centrosome and the abnormal development of brain structure in children. In 2015, Kodani A et al. showed that four microcephaly-related proteins, CDK5RAP2, CEP152, WDR62 and CEP63, were co-located in the centrosome [15]. CDK2 is a kind of cell cycle-dependent kinases, which plays an important role in centrosome replication and cell cycle process, and its centrosome localization requires the interaction of microcephaly-associated proteins as well as their centromeric satellite proteins. The dysfunction of WDR62 can disrupt centrosome replication and stability [15]. In addition, several studies about pedigreespecific deletion of WDR62 revealed that WDR62 contributes to brain growth in neuroblastoma cells and peripheral glial cell lines. The loss of WDR62 in glial cell lines can increase the death risk of neural 
stem cells and significantly reduce the pool of neuroblastoma cells, thus damage the growth of brain. Therefore, the dysfunction of WDR62 in glial cells may also be one of the reasons for the abnormal development of brain structure [16].

West syndrome is an age-dependent disease [17], which may cause by non-specific damages occured at the critical point of brain ontogenesis. ACTH and vigabatrin are currently recommended as the first-line treatments for West syndrome $[18,19]$. We believe that WDR62 missense mutation and frameshift mutation may lead to severe abnormal development of brain structure in this child, which is related to refractory West syndrome. Specific treatments for WDR62 variants have not been reported, though seizure was controlled by valproic acid, vigabatrin and carbamazepine in few patients. However, the clinical manifestations and treatment of refractory West syndrome caused by WDR62 variants have not been paid much attention. Ketogenic diet is effective and tolerated for West syndrome in some reports [20,21], especially combined with vigabatrin [22]. Some adverse effects including hypertriglyceridemia, transient acidosis, poor sleep, and constipation have been reported during this diet $[23,24]$. We also tried ketogenic diet in this case, otherwise, it didn't show any significant advantage than other medicines. Corpus callosotomy is considered as a palliative surgery for drug-resistant epilepsy, which could improve the seizure outcome on some West syndrome [25, 26], especially epileptic spasms. We will try it if we get the consent from his parents.

\section{Conclusion}

In conclusion, due to the variants of WDR62 a phenotype including microcephaly, refractory West syndrome and psychomotor retardation was reported in this case. Further study is needed to explore the relationship between WDR62 variant and epileptic encephalopathy and the specific mechanism involved in the pathogenesis of $\mathrm{MCPH} 2$. Our report enriched the phenotypic and genotypic spectrum of $\mathrm{MCPH} 2$ and West syndrome, indicating that genetic investigation was valuable for children with refractory epilepsy and microcephaly, and will help to further guide early clinical intervention and individualized therapy.

\section{Abbreviations}

ACTH: Adrenocorticotropic hormone; EEG: Electroencephalogram; $\mathrm{MCPH} 2$ : Autosomal recessive primary microcephaly 2; MRI: Magnetic resonance imaging

\section{Acknowledgements}

We thank the patient and his family for sharing the information with this publication, members of Running Gene Inc. for information provided.
Authors' contributions

PZ collected the clinical data and wrote the paper. DC directed the study and revised the paper. QZ, HZ, JL gave some advices and supports on the study. The authors read and approved the final manuscript.

\section{Funding}

The study is supported by Shenzhen Science and Technology Planning Project (JCYJ20160429180424783) and Sanming Project of Medicine in Shenzhen (SZSM 201812005).

Availability of data and materials

Please contact author for data requests.

Ethics approval and consent to participate

The approval of the ethics committee (approval number: Ethical Review Committee of Shenzhen children's hospital [Article] 2019/002) was obtained.

\section{Consent for publication}

The informed consent about publication was obtained from the patient's parents.

\section{Competing interests}

The authors declare that they have no competing interests.

\section{Author details}

${ }^{1}$ Neurology Department, Shenzhen Children's Hospital, Shenzhen, Guangdong 518038, China. ²Division of Growth, Development and Mental Health of Children and Adolescence, Children's Hospital of Chongqing Medical University, Chongqing 400014, China.

Received: 27 November 2019 Accepted: 26 February 2020

Published online: 23 March 2020

\section{References}

1. Miyamoto T, Akutsu SN, Fukumitsu A, Morino H, Masatsuna Y, Hosoba K et al. PLK1-mediated phosphorylation of WDR62/MCPH2 ensures proper mitotic spindle orientation. Hum Mol Genet. 2017;26(22):4429-40.

2. Morris-Rosendahl DJ, Kaindl AM. What next-generation sequencing (NGS) technology has enabled us to learn about primary autosomal recessive microcephaly (MCPH). Mol Cell Probes. 2015;29(5):271-81.

3. Naveed M, Kazmi SK, Amin M, Asif Z, Islam U, Shahid K, et al. Comprehensive review on the molecular genetics of autosomal recessive primary microcephaly (MCPH). Genet Res (Camb). 2018;100(e7):1-16.

4. Woods CG, Bond J, Enard W. Autosomal recessive primary microcephaly $(\mathrm{MCPH})$ : a review of clinical, molecular, and evolutionary findings. Am J Hum Genet. 2005;76(5):717-28.

5. McDonell LM, Warman Chardon J, Schwartzentruber J, Foster D, Beaulieu $\mathrm{CL}$, Majewski J, et al. The utility of exome sequencing for genetic diagnosis in a familial microcephaly epilepsy syndrome. BMC Neurol. 2014;14:22.

6. Bilguvar K, Ozturk AK, Louvi A, Kwan KY, Choi M, Tatli B, et al. Whole-exome sequencing identifies recessive WDR62 mutations in severe brain malformations. Nature. 2010;467(7312):207-10.

7. Shohayeb B, Lim NR, Ho U, Xu Z, Dottori M, Quinn L, et al. The role of WD40-repeat protein 62 (MCPH2) in brain growth: diverse molecular and cellular mechanisms required for cortical development. Mol Neurobiol. 2018; 55(7):5409-24

8. Mahmood S, Ahmad W, Hassan MJ. Autosomal recessive primary microcephaly (MCPH): clinical manifestations, genetic heterogeneity and mutation continuum. Orphanet J Rare Dis. 2011;6:39.

9. Zombor M, Kalmar T, Nagy N, Berenyi M, Telcs B, Maroti Z, et al. A novel WDR62 missense mutation in microcephaly with abnormal cortical architecture and review of the literature. J Appl Genet. 2019;60(2):151-62.

10. Brevik EJ, van Donkelaar MM, Weber H, Sanchez-Mora C, Jacob C, Rivero O, et al. Genome-wide analyses of aggressiveness in attention-deficit hyperactivity disorder. Am J Med Genet B Neuropsychiatr Genet. 2016; 171(5):733-47.

11. Naseer MI, Rasool M, Sogaty S, Chaudhary RA, Mansour HM, Chaudhary AG, et al. A novel WDR62 mutation causes primary microcephaly in a large consanguineous Saudi family. Ann Saudi Med. 2017;37(2):148-53.

12. Banerjee $\mathrm{S}$, Chen $\mathrm{H}$, Huang $\mathrm{H}$, Wu J, Yang Z, Deng W, et al. Novel mutations c.28G > T (p.Ala10Ser) and c.189G >T (p.Glu63Asp) in WDR62 associated with 
early onset acanthosis and hyperkeratosis in a patient with autosomal recessive microcephaly type 2. Oncotarget. 2016;7(48):78363-71.

13. Nardello R, Fontana A, Antona V, Beninati A, Mangano GD, Stallone MC, et al. A novel mutation of WDR62 gene associated with severe phenotype including infantile spasm, microcephaly, and intellectual disability. Brain Dev. 2018;40(1):58-64.

14. Farag HG, Froehler S, Oexle K, Ravindran E, Schindler D, Staab T, et al. Abnormal centrosome and spindle morphology in a patient with autosomal recessive primary microcephaly type 2 due to compound heterozygous WDR62 gene mutation. Orphanet J Rare Dis. 2013;8:178.

15. Kodani A, Yu TW, Johnson JR, Jayaraman D, Johnson TL, Al-Gazali L, et al. Centriolar satellites assemble centrosomal microcephaly proteins to recruit CDK2 and promote centriole duplication. Elife. 2015;4.

16. Lim NR, Shohayeb B, Zaytseva O, Mitchell N, Millard SS, Ng DCH, et al. Glialspecific functions of microcephaly protein WDR62 and interaction with the mitotic kinase AURKA are essential for Drosophila brain growth. Stem Cell Reports. 2017;9(1):32-41.

17. Arita JH, Vale TC, Pedroso JL, Faria EC, Arita FN, Masruha MR, et al. ACTHinduced dyskinesia in a child with west syndrome (infantile spasms). Parkinsonism Relat Disord. 2016;24:145-6.

18. Go CY, Mackay MT, Weiss SK, Stephens D, Adams-Webber T, Ashwal S, et al. Evidence-based guideline update: medical treatment of infantile spasms. Report of the guideline development Subcommittee of the American Academy of neurology and the practice Committee of the Child Neurology Society. Neurol. 2012;78(24):1974-80.

19. Pellock JM, Hrachovy R, Shinnar S, Baram TZ, Bettis D, Dlugos DJ, et al. Infantile spasms: a U.S. consensus report. Epilepsia. 2010;51(10):2175-89.

20. Prezioso G, Carlone G, Zaccara G, Verrotti A. Efficacy of ketogenic diet for infantile spasms: a systematic review. Acta Neurol Scand. 2018;137(1):4-11.

21. Winesett SP, Bessone SK, Kossoff EH. The ketogenic diet in pharmacoresistant childhood epilepsy. Expert Rev Neurother. 2015;15(6): 621-8.

22. Dressler A, Benninger F, Trimmel-Schwahofer P, Groppel G, Porsche B, Abraham $\mathrm{K}$, et al. Efficacy and tolerability of the ketogenic diet versus highdose adrenocorticotropic hormone for infantile spasms: a single-center parallel-cohort randomized controlled trial. Epilepsia. 2019;60(3):441-51.

23. Rai S, Drislane FW. Treatment of refractory and super-refractory status Epilepticus. Neurotherapeutics. 2018;15(3):697-712.

24. Abbasi J. Interest in the Ketogenic diet grows for weight loss and type 2 diabetes. Jama. 2018;319(3):215-7.

25. Chan AY, Rolston JD, Lee B, Vadera S, Englot DJ. Rates and predictors of seizure outcome after corpus callosotomy for drug-resistant epilepsy: a meta-analysis. J Neurosurg. 2018:1-10.

26. Baba H, Toda K, Ono T, Honda R, Baba S. Surgical and developmental outcomes of corpus callosotomy for west syndrome in patients without MRI lesions. Epilepsia. 2018:59(12):2231-9.

Ready to submit your research? Choose BMC and benefit from:

- fast, convenient online submission

- thorough peer review by experienced researchers in your field

- rapid publication on acceptance

- support for research data, including large and complex data types

- gold Open Access which fosters wider collaboration and increased citations

- maximum visibility for your research: over $100 \mathrm{M}$ website views per year

At $\mathrm{BMC}$, research is always in progress.

Learn more biomedcentral.com/submissions 